\title{
Filmic Geographies: Audio-Visual, Embodied-Material
}

Marion Ernwein, University of Oxford

Accepted for publication in Social and Cultural Geography on 14 July 2020.

\begin{abstract}
Although conventionally described as a 'visual' method, film-making is also increasingly used within research on embodiment. However, much remains to be said about the ability of filmic methods to enhance researchers' capacity to think and research through the body. Drawing on my experience of making four research films, in this paper I attempt to advance this agenda in three steps. First, I introduce anthropological work on the filming body to shed light on the technologically-mediated encounters that enfold around a camera and discuss how they might inform geographical thinking. Second, I describe the corporeally-mediated object ecologies that take shape within the filming setting and highlight how a camera might make objects 'speak'. Finally, I discuss the affective dimension of screening research films to research participants and the contribution of such intense events to the articulation of collective matters of concerns. Through these three themes, I make the case for understanding knowledge production as located not merely in encounters with filmed audio-visual content, but also in the embodied-material encounters of bodies and objects around the filming and screening apparatus. I finally discuss the implications of these reflections for conceptualising the 'body' within embodied methods in social and cultural geography.
\end{abstract}

\section{Keywords}

Filmic geography; visual methods; filmic methods; embodiment; objects; affect 


\section{Introduction}

Filmic methods are increasingly popular within geography, with recent filmic productions making strong contributions to areas as diverse as border studies (Lehec, 2019) and urban political ecology (von Heland \& Ernstson, 2018). Although often described as pertaining to the realm of 'visual' (Pink, 2007; Rose, 2016) or 'audio-visual' (Corsi \& Buire, 2019) methodologies, these methods are also increasingly positioned as relevant tools for more strongly ‘embodied' epistemologies (Lorimer, 2010; Simpson 2010). Filmic methods have for instance been deemed capable of evoking embodied practices, postures, and gestures (Lorimer, 2010; Patchett, 2015; Simpson, 2010).

Despite such enthusiasm for researching the body through the camera, however, much remains to be said about filmic methods' potential to generate embodied thinking (McCormack, 2008). The notion that bodies are not only sites of power and experience to be researched but can themselves be 'research instruments' (Hawkins, 2010, p. 324) that fully '[participate] in the cultivation of geographical thinking' (McCormack, 2008, p. 1822) has led to the proliferation of experiments with 'embodied' and 'visceral' methods. Walking (Middleton, 2010), dancing (McCormack, 2008; Veal, 2016), cycling (Spinney, 2006), or cooking and sharing meals (Longhurst et al., 2008) have all emerged as credible modes of generating geographical knowledge. As for filmic approaches, despite Paul Simpson's call for 'a more explicitly bodily video methodology which pays greater attention to the researched/researching body' (2011, p. 344), much still remains to be explored about their capacity to increase a researching body's capacities.

In this paper, I take up Simpson's (2011) call. Reflecting on my own experience of making four short research films within a doctoral project, I bring geographical scholarship into 
dialogue with anthropological literature on filming bodies (de Hasque, 2014; Lallier, 2009; Rouch, 2003) to argue that film-making can be a (more) full-fledged embodied method, understood following McCormack (2008) as a method that cultivates embodied thinking. Specifically, I argue that understandings of 'the body' in 'embodied thinking' should focus not only on the researcher's body, but would also gain from conceiving the filmic apparatus itself as a technical-digital body, which participates in the production of not only 'physical' (Veal, 2016) or 'embodied' (McCormack, 2008), but also material thinking. Furthermore, the encounters that take place around the camera and subsequently the film do not happen between finite, bounded subjects, but are also generative of transpersonal and transcorporeal affective intensities (McCormack, 2003). The notion of 'affective resonance' (Pais, 2016) within the collectives of 'bodies in the room' that make up audiences (Ginters, 2010) has the potential to complexify how we approach 'embodiment' within filmic research. Ultimately, I argue that approaching film-making as an embodied-material, rather than merely audio-visual, method can help to diversify the modalities through which we produce knowledge through filming and to extend understandings of the 'body' within 'embodied' research methods in social and cultural geography in order to encompass not only the researcher's own body, but the technical materiality that equips it and the collective affects the film generates.

The paper is organised as follows. First, I review recent geographical work on film-making as a research method. I also introduce the 'Rouch school' of visual anthropology as well as recent research on objects and interpersonal affects, and further discuss their potential for reconceptualising film-making as an embodied, rather than audio-visual, mode of attending. In the following sections, I describe my own filmic practice, focusing first on embodied encounters around the filmic apparatus, second on the interactions between the latter and other objects in the field. Through this I suggest a re-centring of technical materiality within efforts to perform and understand filmic methods as embodied methods. Finally, moving on to the 
experience of watching the resulting research films, I discuss the role of the shared affective experience of audiencing (Ginters 2010) in allowing research participants to articulate matters of interest and concern.

\section{Form, Content, Encounter}

Often described as pertaining to the 'visual' tradition of the discipline (Pink, 2007; Rose, 2016) geographers' involvement in making films marks the extension of the discipline's expertise in analysing still and moving images (Kennedy \& Lukinbeal, 1997) into the realm of production. In the representational tradition, films are understood to convey meaning through a series of signs and a common filmic grammar. The 'documentary' tradition of filmmaking within academia, which uses edited sequences of images and spoken text to convey ideas - i.e. research results - to an audience, owes much to this tradition. The recent success of films like Into the Inferno (Herzog, 2017) - broadcast on Netflix - and Natura Urbana (Gandy, 2017) screened at multiple festivals - reflects the appetite of funders, festivals, and streaming platforms alike towards such research documentaries.

However publicised and praised, these large budget documentary research films fall short of capturing the breadth and scope of 'audiovisual' (Corsi \& Buire, 2019), 'videographic' (Garrett, 2010), or 'filmic' (Jacobs, 2013, 2016a) geographies - namely branches of geography that are using film-making as a research method in its own right, rather than only for communication or 'impact' (Langdridge et al., 2019). In order to understand the development of such approaches, the role of the post-representational turn in re-enlivening analyses of films needs to be acknowledged. Films, it is recognised, '[are] not just visual but also aural' (Jacobs, 2013, p. 715) - they 'excee[d] the visual realm' (Bates, 2015b, p. 1). What distinguishes films from other media is their capacity to evoke and convey movement (Deleuze, 1983). In-shot movement, camera movement, editing-induced sense of movement: all these take film beyond 
the audio-visual; they evoke, for instance, kinaesthetic sensations of bodily in/stability and mobility. Understood this way, films offer 'a mode of evocation that does not immobilise or flatten' existence (Bates, 2015a, p. 24). Such renewed theoretical engagement with films has in part been fuelled by the 'experimental imperative' to 'amplify other sensory, bodily and affective registers' than the visual (Whatmore, 2006, p. 606). It has percolated into modalities of using cameras and other recording devices.

Beyond the established (though by no means static - see Nichols, 1983) genre of the documentary, experimental modes of filming and making films have bloomed in geographical work, testifying to modes of engaging with their more-than-visual and more-than-narrative character. Working on the resonances and dissonances between visual and auditory, sonic geographer Michael Gallagher (2015), for instance, has shown how experimental engagement with the relation between these two layers of information can give rise to "a radically reconfigured interaction between listener, sound and environment" (2015, p. 182) and challenge modes of attending to the affective quality of space. Embodiment features centrally within geographers' rationale for working with video in that more experimental register. Researchers highlight the potential held by research footage to witness and evoke embodied practice and sensoriality (Bates, 2015a; Jacobs, 2016b; Patchett, 2015). They underline the capacity of video analysis and editing to make researchers engage with research material in a manner more attuned to embodiment (Jacobs, 2016b; Simpson, 2011, 2015). For instance, in order to study the body as a site of affective experience and intervention in street performance, Paul Simpson (2011) used a camera as an extension of his own body's sensing capacities, and sought to recall bodily interactions with passers-by through watching footage. A few years later, Simpson et al. (2015) used multi-angle filming to capture the securitised atmosphere of international train stations, thus experimenting with a new method for researching the ephemeral affective states produced through the ordering of bodily mobilities and interactions. 
Despite enthusiasm for researching embodiment through filmic methods, however, the capacity of the latter to convey the embodied/affective quality of social life is limited. A commonality between these filmic writings is their focus on footage - i.e. on the moving images and sounds themselves - and what it allows researchers to do - such as witnessing the sensate (Bates, 2015a; Patchett, 2015). However, footage of interactions with passers-by, Simpson argues, 'did not actually show the affective relations' he was hoping to capture when researching street performance - at best, repeated viewing facilitated reflection on them (Simpson, 2011, p. 350). In much the same way, Simpson notes, watching train station footage from one's office 'only provides a partial and limited sense of what was in fact taking place' (Simpson, 2015, p. 44). Accordingly, 'such atmospheres and ambiances are to be experienced in their midst, in the middle of these events and parameters' (idem). Thus Simpson advocates 'a more explicitly bodily video methodology which pays greater attention to the researched/researching body' $(2011$, p. 344) and a more performative ethos, allowing 'researchers to become caught up in the inflow of everyday life, and better understand their ever-evolving situation within this' (Simpson, 2015, p. 45).

This paper takes up Simpson's call for a 'more explicitly bodily video methodology' (2011, p. 344). It also concurs with Kim Kullmann, who argues that the knowledge produced through filming that does 'not [necessarily] result in images but may still be significant' (Kullmann, 2015, p. 53) needs to be better understood. That is, the embodied practice of filming itself, the event of being in the midst of things with a camera in hand ${ }^{i}$. In this paper, therefore, I conceive of filming as an encounter and an event, embodied and material as much as auditory and visual. I find inspiration in anthropological writings on the filming body. Within the field of anthropology, Jean Rouch (see e.g. Rouch, 2003) is a key figure for those interested in problematising the link between filming and embodied methods. Anthropologist-cumfilmmaker Christian Lallier writes that Rouch 'radically broke up with the conventional 
approach to documentary making' by placing the relation between filming and filmed at the centre of his approach (Lallier, 2009, p. 73). For Rouch, the faithfulness of a documentary film should not be judged against the 'authenticity' of that which is being filmed, but against the 'sincerity' of the relation between the filmed and the filming. Finding such sincerity requires learning to attend to others through the whole body: by finding correspondency with the movement of those being filmed, one may enter their social world, rather than observe it from a distance (see Lallier, 2009, p. 71). Filming, therefore, is less a matter of capturing content or producing form, than of attending to, and encountering, others.

With their focus on the embodied practice of filming, these anthropologists' work helps to shift the focus from what can be captured through a camera, to what the camera, when being held and moved by an affected body, does to the process of research. I see in such ideas an invitation to conceive of the production of knowledge as located in the moment of filming, not just in the stage of reviewing the filmed material - a notion that resonates with the idea of research as a performance (Veal, 2016). However, I believe that recent work on materiality and affect can help to translate these ideas more forcefully into social and cultural geography, for two reasons.

First, anthropological work on the filming body is body-centric, at the expense of reflections on the place of the body in a broader set of material relations. In this paper I show that approaches to materiality and objects in geography can renew our understanding of the role of the camera in embodied filmic encounters - notably through its networked relations not just with human bodies but also with other objects. Spurred by the 'material' (Whatmore, 2006) at least as much as the 'embodied' turn, and inspired by object-oriented ontologies (Harman, 2018), recent work in geography has attempted to produce object-centred understandings of the production of space and place, focusing on objects' properties and their vital materiality. For instance, James Ash (2015) describes how ‘... affects are generated through encounters between technical objects within an ensemble and translated, which in turn generates particular 
affects as humans encounter them' (p. 87). Far from being inert, objects gain a capacity to affect from their connection within a wider network of other material things. I put these ideas to work by arguing that researching with a camera creates unexpected connections with a range of objects and things which can 'speak back' and inform the research. In that sense, the notion of embodiment extends beyond the body of the researcher, to include the material capacities of objects and their technical bodies.

Second, if the bodies I write about are not only human, neither are they just bounded containers of individuality. Recent work in cultural geography has spurred fascinating insights on the capacity of transpersonal affects to circulate and generate atmospheres. In the final section I bring into dialogue Jean Rouch's concept of shared anthropology and recent work on affective intensities both in geography (Ash 2012, 2015; McCormack, 2003) and in media and performance studies (Hanich, 2014; Pais, 2016). I argue that film-watching as a shared transpersonal embodied experience can also constitute a heuristic event with a generative affective stickiness. But first I introduce the context of my research and the (evolving) rationale for working with film.

\section{Filming as Mode of Attending}

The research project within which the four research films were produced was broadly concerned with urban environmental management in Geneva (Switzerland). Specifically, the project sought to examine the ways in which the adoption of new ecological and participatory modalities of urban greening, which marked a rupture from top-down horticultural planning and environmental management, had translated into the work practices and occupational identities of maintenance workers employed by local councils in the Geneva canton. The research examined how such transformations required park workers to adopt new modalities of attention, modes of looking after nonhuman nature, and ways of interacting with the public. 
I spent six months, across two years, following three crews of municipal gardeners in their daily work routines and occasionally interviewing them, as well as spending time in municipally-organised community gardens - resulting in four 20-minute research films. Filming was built in as a core part of the research as I endeavoured to capture the visual character of the new vegetal designs and arrangements produced, as well as to witness the gestures, interactions, and affective expressions constitutive of work.

As mentioned, my main sources of inspiration were in the Rouch school of visual anthropology. Following Christian Lallier (himself following Frederick Wiseman), my set concept was to film to observe rather than observe to film. Lallier describes 'observing to film' as the conventional documentary approach, which pre-supposes to 'determine the object of our attention before we record it' (Lallier, 2009, p. 53) ${ }^{\text {ii }}$. For Lallier, such an approach is problematic insofar as: 'if I identify and describe an action in the ultimate goal of determining what I could film, I consider the event not as the particular circumstance of an experience, but as a typical situation illustrating a reproducible model' (Lallier, 2009, p. 54) ) $^{\mathrm{iii}}$. The event, therefore, loses its 'eventual' quality, and the 'experience' is turned into a representation. If instead, turning this approach on its head, 'I film in order to observe, then it means that I observe "through" what I film' (Lallier, 2009, p. 54, - emphasis in the original) ${ }^{\mathrm{iv}}$. Here it is important to note the absence of a 'then' between 'to film' and 'to observe': I don't observe what I have filmed; rather, I put myself in condition to observe through the act of filming itself. Therefore, despite the tens of hours of footage that I collected, I did not seek to build a film archive for the purpose of later video-analysis. I did look at the footage over and over again, yet not to analyse the material as though it was 'content', but in the perspective of editing films. Working within such an approach, I initially sought to use the camera to educate my attention (Ingold, 2001) and attune to park workers' ways of looking (Grasseni, 2009). With park workers pointing to relevant observations and showing me how to look at them, I learnt to 
understand their practices through the lens of the camera ${ }^{1}$. However, as I further develop below, I quickly realised that, when holding a camera, I was attending through my whole body rather than merely through my eyes ${ }^{\mathrm{v}}$, and that the filming apparatus was playing many more roles than that of recording device. This new apprehension of the location and nature of knowledge production transformed the way I approached the camera, resulting in my shifting from researching embodiment through filmic methods to researching through embodied filming.

With each group of workers I collaborated with, the contract, collectively negotiated and agreed upon, was the following: I would film their work routine and interview them in order to produce a 'portrait film' of the work collective, their practices, and their reflections. That way, I could spend time observing work and training my attention, much in the position of an apprentice, while at the same time constructing a media through which to generate further exchange and conversation. Therefore, heuristic encounters happened not only through filming, but also through watching the resulting films. The 'film portraits' I edited were arranged around sequences, which problematised various aspects of work. I borrowed from Pierre-Marie Stassart and Valérie Mathieu (2011) the idea of regularly staging conversations about footage with research participants in order to collectively arrive at a final film. I designed a five-stage process, comprised of: a) initial group discussion, b) period of filming and editing, c) group screening and discussion, d) further filming and editing, e) final screening. During each of the screenings, the discussion was structured by the sequences in the film, which I used to prompt debate on topics I deemed relevant to my research and to the work collective in question. As I develop below, drawing inspiration from Rouch's concept of shared anthropology, rather than endpoints, the screenings became key events in orienting my research. Filming within a work setting came with ethical issues, pertaining notably to the 'truth effect' of images and the 
potential risk of disclosing opinions or practices from workers that were not aligned with health and safety regulations or with the views of management. In that sense, the screenings were not only driven by an agenda of elicitation, but also by the ethical commitment to make the films safe to screen.

It wasn't a straightforward success-story. At one point, the camera (which belonged to the University) fell from the tripod and broke, which led to an almost farcical situation where neither my nor the university's insurance agreed to cover the costs of repair. There was also something nerve-wracking about the screenings, particularly as a young female presenting her research to groups of largely male, quite vocal, council workers within their 'natural' work environment. That gendered aspect, however, was balanced by my otherwise quite powerful role as the one in charge of 'making images'; and while I experienced misplaced bodily interactions a few times during the research, these were never while I was filming or presenting the films. If anything, my filming apparatus and status as filmmaker might have given me an easier time within a largely masculine sector.

In the remainder of the paper, I use ethnographic vignettes to explore how conceiving of filming and film-making as an embodied-material mode of attending, and of the collective experience of watching research films as affective event, might help to push the agenda of embodied methods in social and cultural geography further.

\section{Technologically mediated embodied encounters}

On a sunny August morning, camera in hand, I followed one of my research participants on his morning rubbish-picking routine. Walking alongside him, I adopted his pace and attitude to film over his shoulder. As he stopped, bent forward, and picked up rubbish, I kneeled to the ground to film from below. I cultivated similarities and proximities between his corporeal 
movements and mine. I learned to understand the movements implicated in his work through my own body.

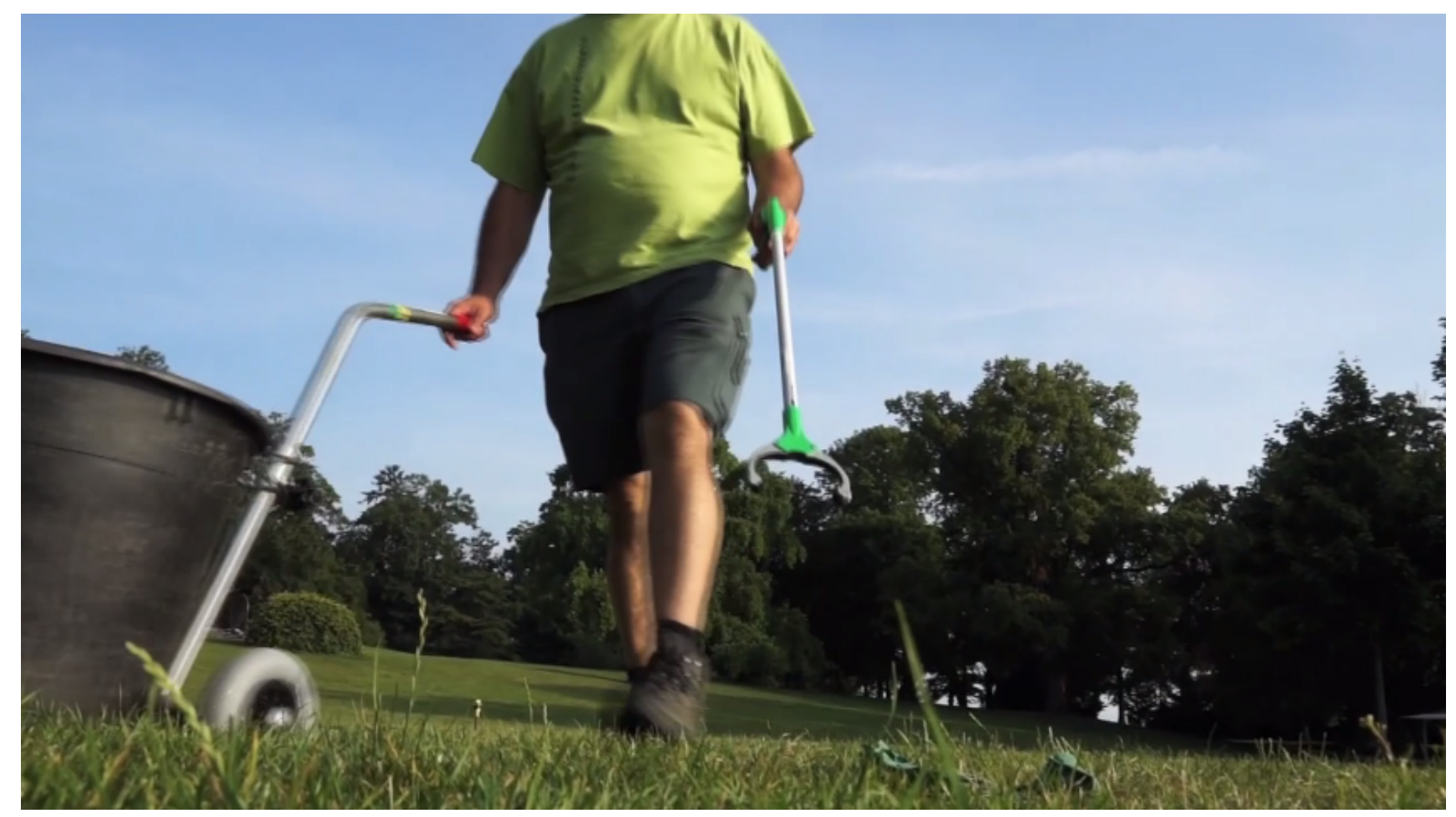

Figure 1: Litter-picking filmed from a ground-kneeling position.

In this section, I stage a conversation between my fieldwork experience and anthropological work on the filming body, I discuss how holding a camera helped me attune to my research partners' worlds through the body at least as much as through the lens. Distancing myself from some of the assumptions of this body of work, in particular its emphasis on hand-holding the camera, I argue that, far from hindering embodied knowledge, using a tripod helped to multiply the sensory registers through which research was performed, and knowledge generated and discussed. This allows me to introduce reflections on the filming apparatus's material excesses, which I elaborate on in the next section.

The idea of attuning to the embodied rhythms of the filmed subjects, their pace, and their attitude, is co-extensive to the birth of the moving picture. When studying the movement of wings in birds' flight in the 1880s, French physiologist Etienne-Jules Marey devised a chronophotographic apparatus which relied on physical connection between the camera and 
the bird's wings, each movement spurring a photograph (Lallier, 2009, p. 14). In my research, instead of being directly activated by my partners' movements, the connection between the camera and my partners' bodies was mediated by my own adoption of close, or similar, postures and rhythms. The camera gave me a valid excuse for learning to experience my research partners' work through my body: without a camera in hand, the proximity of my body to my partners', my adoption of postures similar to theirs, would, at best, have been seen as eccentric, if not inappropriate. However, the camera justified a presence-by-the-side and a close attuning to bodily rhythms and attitudes. Whether or not it resulted in 'good' or usable footage, this dimension of filmic research is significant: it justified allowed me to gain a close embodied understanding of the practices I was researching. Such celebration of the handheld camera's ability to connect bodies is not uncommon in visual anthropology. Rouch precisely started to experiment with his reflexive and relational approach to film-making when the possibility of using hand-held, mobile cameras, synchronised with sound capturing devices, emerged. His 'Ciné-transe', for instance, is predicated upon the use of a fixed-focal, hand-held camera: with no zoom and no tripod, there is no solution other than movement to get close to the action one is filming/researching. Filming, therefore, does not originate merely from one's eyes, but from one's whole body.

Owing much to Rouch's legacy, tripods are commonly held to introduce distance and disengagement (Lallier, 2009; Rouch, 2003). Today however, a wide range of small digital cameras, SLRs, and even smartphones, can be used on compact tripods, which are portable and mobile, in contrast with the bulky tripods required for heavy cinema cameras. In any case, a fixed camera+tripod apparatus can do more than create distance: it can stimulate the mobility of bodies around itself and multiply the types of encounters that can happen whilst performing filmic research. I sometimes left the camera to record on its tripod while moving around it or walking to its front to interact with the workers. This bodily choreography around the tripod 
provided research partners with opportunities to peep at the camera's digital screen and look at what is being filmed. Occurrences abounded of research participants getting behind the camera to reframe the shot, or suggesting alternative viewpoints on an action being filmed, therefore reversing roles of the observing and the observed. In that sense, and somewhat contraintuitively, while the camera allowed me to learn through the body, occasionally leaving the camera on the tripod and taking some distance from it allowed my research partners, by guiding the camera's orientation and focus, to tell me something about how best to look at a specific gesture or interaction. The tripod, therefore, was key to diversifying the sensory dimensions through which research was conducted, and for attuning to my partners' world by learning to see like them through the lens of the camera (as in Grasseni, 2009). It allowed me to develop a practice of looking that gave my research partners an active role in guiding my attention, making my practice of attending a matter of debate and discussion.

\section{Corporeally mediated object ecologies}

In the second year of my fieldwork, embarking on research with a new parks team, I decided to spend the first day building rapport with my new research partners, and did not take the camera with me. And so, on a rainy Spring day morning, I stood alongside park workers as they uprooted tulips and fed the soil. Standing in wet grass, with soaked feet, cold hands, and a damp notebook, I struggled to find my place, between proximity and distance, commitment to observation and quest for some degree of comfort. I finally found a more or less sheltered bench close by, which I decided to sit on to continue observing and take some initial notes. Because of its location, and perhaps more importantly its fixity, the bench imposed a fixed distance between the workers' labouring bodies and mine. I was sat, cold and wet, writing a few lines, occasionally looking down, while all the workers were up and about. A couple of workers came to see me, one joking: 'have you stopped working already?', the other asking 
concernedly: 'are you ok here on this bench?'. I felt decidedly awkward, and rather out of place. The next day, camera on the tripod and in the sun, standing close to the park workers, partaking in exchanges, and visibly active, the jokes ceased. Instead, interest towards my project rose, and my own awkwardness receded. I used a small, though professional-looking camera, with a mounted microphone and a photo tripod - bulky material, but transportable on an e-bike. With their size and portability broadly corresponding to the tools used by the gardeners, it immediately struck me that my camera and tripod were directly echoing my research partners' tools, helping to place me as a worker. They had their scythe or their lawnmower, I had my filming equipment. I would, like my research partners, walk from site to site with my tools. I would, like they did, put my tools away during coffee and lunch breaks, occasionally look after them, and express concern when they did not seem to work right. The filming equipment was the tangible proof of my work.

In this section, I shift the focus from the relation between the filmic apparatus and bodies to that between technical objects themselves. Just as bodies were re-centered within geographical understandings of the production of space, place and power, so were objects. While described by 'old' materialists as 'dead' or 'ossified' labour (Kirsch \& Mitchell, 2004), things are shown by 'new' materialists to always excess the labour that is put into them. Even apparently hard and cold matter has a degree of instability, a vibrancy (Bennett, 2009) that new materialist scholars have been busy integrating within re-materialised understandings of social formations. Object-Oriented-Ontology-influenced post-phenomenology (Ash \& Simpson, 2016) for instance attempts to decentre the notion of experience from the human subject through experimental thought into the 'autonomous existence of objects' (ibid, p. 49). Within those fields of inquiry, objects have something of a lifeworld of their own: despite their embedding social relations, they 'only disclose some of their qualities, depending on what [other objects] they encounter' (idem). Through 'pondering their nature and relations with one another as 
much as with ourselves' (Bogost, 2012, p. 6, cited by Ash \& Simpson 2016, p. 49), one can explore 'ecologies of objects' and unpack how '[arrangement of] objects' components and the objects themselves [shape] potentials and possibilities for affecting different bodies' (Ash, 2015, p. 85). For the purpose of this paper, this will allow moving the notion of performance beyond a technologically-mediated interaction between bodies, to show that it is also a matter of corporeally-mediated interaction between objects. I consider two types of 'ecologies of objects' and the resonances between my filming apparatus and them: the working tools and the digital technologies.

First, then, the similarities in shape, size, weight, and portability between my filming equipment and the gardeners' tools sometimes allowed the former to work as a proxy for the latter. When observing park workers interact with a bed of perennial plants, I was invited to get into the action. Kneeling down beside them, I moved my camera into the flowerbed, like they were moving in their scissors and secators. I would not have moved my notebook into the flowerbed; yet the camera's shape and size allowed me to be by the side of my research partners and to, to some extent, mimic their own professional gestures to film them. Talking about our tools also became something of a recurring theme in our daily conversations. One of my films ends with a gardener moving his tool - a fork - towards my camera and cheerily explaining that it just broke, highlighting how our work instruments served to link us and create some degree of shared understanding.

As noted by Lallier (2009, p. 21), 'the film-maker appears like one of these craftspersons, recognised for their skill, and defined through their association with a technical object'vi Indeed, through its resonance with the workers' tools, the camera gave me a relatable social status and helped to position me as a member of the social field. However, tools were neither the only, nor always the main, component of the ecology of objects my camera took part in. 
Although they were not the focus of my research, digital technologies happened to be ubiquitous, and the camera also gained agency by interacting with them.

On another first day of fieldwork ${ }^{\mathrm{vii}}$, I had showed up at the horticultural production centre of a suburban town. While all employees had previously had the opportunity to discuss the project with me and had unanimously decided to welcome it, I was taken to a corner by one of them. Visibly cross by my presence, he warned me: 'Don't approach me. No filming, no questions, no attention'. Slightly shaken by this less than friendly introductory encounter, I spent the rest of the morning avoiding him, staying instead close to a cheery group of female employees. That same afternoon, the head manager sent me to work with a group of men. To my dismay, the group included that morning's cross man. Careful not to pay him any attention, I interacted with his colleagues, who showed me how their experiential knowledge allowed them to carefully decide what distance to allow between the plants they were putting in a flowerbed. After an hour or so, the person who had so strongly opposed me in the morning asked me if he could take a look at the camera. He suggested I should replace him for a moment and plant some of the flowers while he films. After about 10 minutes, he called me to show me what he had filmed. He then added: 'I'm going to show you something. I trust you to not tell him about it, but with other colleagues we've made a short film about our boss'. And so, they showed me the film they had secretly shot and edited. We talked about the film, about the work relations within the service, and this person became one of my main interlocutors in the team.

As a portable digital device, the camera, and its being directly handled by one of the employees, had called forth memories of similar devices and their past use. The camera interacted with my research partners' own digital devices, their affordances and uses, and the traces thereof. This is not to say they would not have shown me the video had I not had a camera, but it certainly helped to start a conversation on work relations. The camera, it this sense, detains a degree of agency, in the sense of acting held dear by ANT scholars of irrupting and altering the normal 
course of things. The camera, as it is, is made to act by the one who films: the red light that comes off while recording, the moving outwards and inwards of the lens, and the small mechanical noises such movements make, are enough to alter the normal course of things: postures changed, exchanges of looks with the researcher avoided. But further to these intuitive understandings of how a camera might act, it also inter-acts with other objects - both within a distributed network of things and within a sociotechnical field. It interacts with past and present objects and their remaining traces in the present experience. It brings some of them back to memory, along with the manifold stories that accompany them.

\section{Affective resonances}

Fast-forward to encounters with and around the films. Drawing on Jean Rouch's concept of shared anthropology, I conceived the screening of intermediary and final versions of my films as heuristic events. I edited my films to ensure that they would elicit discussions relevant to the key questions of my research. And so they did. The screenings, indeed, provided research participants with an occasion to decode my research. Because of my own research interest, I had asked the park workers to 'show me their work'. Every day, I had met up with them in one place or another, where they were cutting grass, pruning a hedge, or planting flowers. There was an instance when, after screening the resulting film, the workers expressed surprise: why did the riverside cliffs and forests not appear? Why did the film focus so much on parks, roundabouts, and flowerbeds? By asking them to guide me through their work, my attention had been focused on the most labour-intensive spaces. For many employees, however, lessintensively managed spaces were what kept them going. My prompt to have them show me their work, by focusing on the where and what, had obliterated the why.

However, the collective screenings did more than provide research partners with an occasion to scrutinise and critique my work. Nine months had passed since I had shot the last scenes 
when I screened one of my films to the parks workers I had filmed. In the meantime, it had been made mandatory for all of them to wear a uniform. When they saw themselves on the screen, the workers were suddenly brought back to the pre-uniform time. After the initial phase of laughter, during which they gently teased each other about their personal clothes, they expressed deep frustrations at what many interpreted as an increase in the power of their hierarchy. The discussion then moved on to evolving modes of monitoring individual and collective work and to a recent decrease in the workforce. In the same discussion, the workers also told me that even though the film was 'impressive', the 'nice, glossy' images (which I was proud of) were at odds with the current ambiance within the municipal service. I had not realised at the time, but many employees were involved in a union dispute over the workforce decrease and new modalities of surveillance and monitoring just mentioned (see Author, in press). The collective encounter with the film forced me to look back at my observations and reinterpret some of them in a new light, which oriented the subsequent twelve months of my research.

Whilst conducting follow-up research a couple of years later, I bumped into one of my interviewees, who told me how the film, and particularly the experience of watching it together, had stayed with him. He recalled how everybody had laughed during one of the scenes and reflected on the way that laughter had helped to articulate a collective stance when many of the issues raised had previously been addressed within the personnel's committee and the union, but not within the work team itself. Experiencing the film together, recollecting past times, but also more mundanely laughing and bantering, all played a role in allowing perspectives to collectively emerge and afforded those affects enough intensity to stick both with me and with (some) participants even after the event.

Here I want to argue that the eventful character of the screenings was as generative as the friction between the content of the film and the participants' work-world (exemplified above 
in some workers' surprise at the absence of cliffs and forests in one of the films). This 'eventful' character was, to a certain extent, curated - typically by bringing fruits, pastries, and coffee to create a relaxed atmosphere. The projections all happened during the employees' work hours, thus marking a rupture in their work routine. On two occasions, the screenings also entailed repurposing a common room which had not been designed for that kind of event. Yet what gave screenings their eventful character was not just a sense of disruption but also of intensity - the sense of togetherness, the collective co-presence and shared audiencing of a visual, auditive, and kinaesthetic experience. Put simply, while it is possible to sit in a room and read a similar article together, individuals will read at their own pace and can move back and forth in the paper; when it comes to watching a film together, however, the pace is imposed on the spectators, who share an embodied exposure to sounds, images, and rhythms. The beingtogether of the audience in a dark room subjects it collectively to the loudness of sounds, the brightness (and in my case sometimes the blurriness) of images, and all the common memories associated with them - a co-modulation of affect by the physical being-in-common and the subjection to an affect-amplifying force (Ash, 2012). Far from a deterministic transfer of affect from the media itself onto the audience, much of the intensity is generated through the attention, tension, and outbursts of laughter among the audience.

Contemporary research in media studies on shared aesthetic experiences (Shanklin \& Meyer, 2019) and the phenomenology of collective spectatorship (Hanich, 2014) points to the role of common expectations, the joint bodily experience of immobility, and the sense of joint attention, in shaping the affective experience of watching a film together, and sparking the emergence of 'affective alliances' (Grossberg, 1984, cited by Jerslev, 2001). Within performance studies, research is also moving away from understanding an audience's work as a work of 'receiving' and 'decoding' signs to that of circulating, amplifying and producing affect (Pais, 2016). Therefore, as 'moving images of moving bodies allow rhythms, movements 
and affects to emerge, circulate and travel across time and space' (McCormack, 2008, p. 1832), these are circulated and reverberated - gaining in intensity through their circulation - across an audience which is always more than the sum of its individual bodies. 'Doing' embodied filmic methods therefore also requires embracing screenings themselves as corporeal events, yet events where individual bodies leave room to transpersonal affects and intensities.

\section{Conclusion}

The paper started with a discussion of the place of filmic methods within efforts to develop 'embodied' research methods in geography. It highlighted that although filmic methods' contributions to researching embodiment are clear, their capacity to generate embodied thinking - to increase a researcher's bodily attentiveness - remains to be assessed (as also argued by Simpson, 2011). Therefore, by focusing on what happens when experiencing 'the midst of events' through a filmic apparatus, the paper sought to diversify understandings of how filmic methods can help to produce knowledge. Through paying attention to filming bodies, object ecologies, and collective affective experiences, the paper carried out a double de-centering: of the 'visual' within filmic methods and of individual bodies within 'embodied' methods. It ultimately makes three contributions, all of which have implications both for filmic methods specifically and for embodied methods in social and cultural geography more broadly.

First, through a detour into anthropological writings on filming, I argued that far from a simple act of recording a scene through a lens, filming in fact requires attending through the whole body. I have argued that the camera and its tripod can mediate creative bodily relations, not only multiplying the registers of bodily attention but also forcing a more explicit reflection on them, therefore giving centre stage to bodily relations in thinking.

Second, while it seems obvious that the camera mediates between bodies, the filming body in fact simultaneously mediates between and organises an ecology of objects, such that the camera 
interacts with other technical and digital objects. The physical resemblances and material resonances between the filmic apparatus and the broader ecology of past and present objects can make a range of objects otherwise quasi invisible and practically mute force themselves onto attention and into thinking.

Finally, relations within a filmic geography project are mediated not only by the filmic apparatus, but also by the promise of a film and of course by the film itself. The transcorporeal affects that circulate within collective audiences assembled during a film screening generate both short-term and longer-term effects. Although screening events generate dense affective intensities with immediate effects, their eventful character, that is, their capacity to disrupt routines, lies in their ability to stick, which can only be grasped on the longue durée.

These arguments have broader implications for the way we think and practice 'embodied' research and thinking. They challenge common assumptions about where bodies start and end when doing 'embodied' research, pointing to the necessity to give up on purified categories of direct, unmediated phenomenology versus disembodied, technologically-mediated research. One might also speculate about the future of the role of the body within increasingly digitallymediated modes of performing research. Although in the research discussed in this paper, the camera made objects past and present come to attention by being held and actioned by the researcher, objects are also increasingly connected to each other, whether through Bluetooth technology or the Internet of Things. This connectedness opens up a whole spectrum of possibilities for object-based ethnographies, whereby not only researchers and research participants, but also for instance their phones, interact and learn from each other (Pink et al., 2017). It might, however, also raise the question of who really is researching or being researched, when the technologies used gather as much, or probably much more, information, as does the researcher. 


\section{References}

Ash, J. \& Simpson, P. (2016). Geography and post-phenomenology. Progress in Human Geography, 40(1), 48-66.

Ash, J. (2012). Attention, videogames and the retentional economies of affective amplification. Theory, Culture \& Society, 29(6), 3-26.

Ash, J. (2015). Technology and affect: Towards a theory of inorganically organised objects. Emotion, Space and Society, 14, 84-90.

Bates, C. (2015a). Intimate encounters: Making video diaries about embodied everyday life. In Bates, C. (Ed.), Video methods: Social science research in motion (pp.10-26). Routledge.

Bates, C. (2015b). Introduction: Putting things in motion. In Bates, C. (Ed.) Video methods: Social science research in motion (pp. 1-9). Routledge.

Bennett, J. (2009). Vibrant matter: A political ecology of things. Duke University Press.

Corsi, L., \& Buire, C. (2019). Géographies audiovisuelles: Des géographes-réalisateur.rice.s entre création, participation et mediation. [Audiovisual geographies: Geographers-cumfilmmakers between creation, participation and mediation][Special issue]. Revue Française des Méthodes Visuelles, 3.

De Hasque, J.-F. (2014). Corps filmant, corps dansant. [Filming body, dancing body]. Parcours Anthropologiques. 9.

Deleuze, G. (1983). L’image-mouvement. Cinéma 1. Les Editions de Minuit.

Gallagher, M. (2015). Working with sound in video: Producing an experimental documentary about school spaces. In Bates, C. (Ed.), Video Methods: Social Science Research in Motion (pp. 165-186). Routledge. 
Garrett, B. (2010). Videographic geographies: Using digital video for geographic research. Progress in Human Geography, 35(4), 521-541.

Ginters, L. (2010). On audiencing: the work of the spectator in live performance. Performance, 10.

Grasseni, C. (Ed.). (2009a). Skilled visions: Between apprenticeship and standards. Berghahn.

Grasseni, C. (2009b). Good Looking: Learning to be a cattle breeder. In Grasseni, C. (Ed.), Skilled visions: Between apprenticeship and standards. Berghahn.

Hanich, J. (2014). Watching a film with others: Towards a theory of collective spectatorship. Screen, 55(3), 338-359.

Harman, G. (2018). Object-oriented ontology: A new theory of everything. London: Penguin.

Hawkins, H. (2010). 'The argument of the eye'? The cultural geographies of installation art. Cultural Geographies, 17(3), 321-340.

Ingold, T. (2001). From the transmission of representations to the education of attention. In: Whitehouse, H. (Ed.), The debated mind. Evolutionary psychology versus ethnography. Berg.

Jacobs, J. (2013). Listen with your eyes: Towards a filmic geography. Geography Compass, 7(10), 714-728.

Jacob, J. (2016a). Filmic geographies: the rise of digital film as a research method and output. Area, 48(4), 452-454.

Jacobs, J. (2016b). Visualising the visceral: using film to research the ineffable, Area, 48(4), 480-487.

Jerslev, A. (2001). "Video nights". Young people watching videos together - a youth cultural phenomenon. Young, 9(2), 2-17. 
Kennedy, C., \& Lukinbeal, C. (1997). Towards a holistic approach to geographic research on film. Progress in Human Geography, 21(1), 33-50.

Kindon, S. (2003). Participatory video in geographical research: a feminist practice of looking? Area, 35(2), 142-153.

Kirsch, S., \& Mitchell, D. (2004). The nature of things: Dead labor, nonhuman actors, and the persistence of Marxism. Antipode, 36(4), 687-705.

Kullman, K. (2015). The mobile life of screens: Digital imaging on school journeys in Helsinki. in Bates, C. (Ed.), Video methods: Social science research in motion (pp. 49-70). Routledge.

Lallier, C. (2009). Pour une anthropologie filmée des relations sociales. [For a filmic anthropology of social interactions]. Editions des Archives Contemporaines.

Langdridge, D., Gabb, J., \& Lawson, J. (2019). Art as a pathway to impact: Understanding the affective experience of public engagement with film. The Sociological Review, 67(3), 585601.

Longhurst, R., Ho, E., \& Johnston, L. (2008). Using 'the body' as an 'instrument of research': kimch'i and pavlova. Area, 40(2), 208-217.

Lorimer, J. (2010). Moving image methodologies for more-than-human geographies. Cultural Geographies, 17(2), 237-258.

McCormack, D. P. (2003). An event of geographical ethics in spaces of affect. Transactions of the Institute of British Geographers, 28(4), 488-507.

McCormack, D. P. (2008). Geographies for moving bodies: Thinking, dancing, spaces. Geography Compass, 2(6), 1822-1836.

Middleton, J. (2010). Sense and the city: exploring the embodied geographies of urban walking. Social and Cultural Geography, 11(6), 575-596. 
Nichols, B. (1983). The voice of documentary. Film Quarterly, 36(3), 17-30.

Pais, A. (2016). Re-affecting the stage: affective resonance as the function of the audience. Humanities, 5(3), 79.

Parr, H. (2007). Collaborative film-making as process, method and text in mental health research. Cultural Geographies, 14(1), 114-138.

Patchett, M. (2015). Witnessing craft: employing video ethnography to attend to the morethan-human craft practices of taxidermy. in Bates, C. (Ed.), Video methods: Social science research in motion (pp. 71-94). Routledge.

Pink, S. (2007). Doing visual ethnography. SAGE.

Pink, S., Sumartojo, S., Lupton, D., \& Heyes LaBond, C. (2017). Empathetic technologies: digital materiality and video ethnography. Visual Studies, 32(4), 371-381.

Richardson-Ngwenya, P. (2012). The affective ethics of participatory video: an exploration of inter-personal encounters. ACME: An International Journal for Critical Geographies, 11(2), 250-281.

Rose, G. (2003). On the need to ask how, exactly, is geography “visual”? Antipode 35(2), 212221.

Rose, G. (2016). Visual methodologies: An introduction to researching with visual materials ( $4^{\text {th }}$ ed.). SAGE.

Rouch, J. (2003). Ciné-ethnography. University of Minnesota Press.

Shanklin, R., \& Meyer, M. (2019). Going together: Toward an account of sharing aesthetic experiences. Journal of Aesthetic Education, 53(3), 106-124.

Simpson, P. (2011). "So, as you can see...": some reflections on the utility of video methodologies in the study of embodied practices. Area, 43(3), 343-352. 
Simpson, P. (2015). Atmospheres of arrival/departure and multi-angle video recording. Reflections from St Pancras and Gare du Nord. In Bates, C. (Ed.), Video methods: Social science research in motion (pp. 27-48). Routledge.

Spinney, J. (2006). A place of sense: a kinaesthetic ethnography of cyclists on Mont Ventoux. Environment and Planning D: Society and Space, 24(5), 709-732.

Stassart, P.-M., Mathieu, V., \& Mélard, F. (2011). Reflexive audiovisual methodology: The emergence of "minority practices" among pluriactive stock farmers. Journal of Rural Studies, 27(4), 403-413.

The Author. (in press). Bringing urban parks to life: the more-than-human politics of urban environmental work. Annals of the American Association of Geographers.

Veal, C. (2016). A choreographic notebook: methodological developments in qualitative geographical research. Cultural Geographies, 23(2), 221-245.

Whatmore, S. (2006). Materialist returns: practising cultural geography in and for a more-thanhuman world. Cultural Geographies, 13(4), 600-609.

\section{Filmography}

Gandy, M. (2017). Natura Urbana: The Brachen of Berlin.

Herzog, W. (2017). Into the Inferno.

Lehec, C. (2019). The Walls of Deisheh.

Von Heland, J., \& Ernstson, H. (2018). One Table, Two Elephants. 
${ }^{\mathrm{i}}$ While researcher-led experiences of filming tend to focus on the production of content, which could be at the expense of all that a camera does beside producing footage, scholars working within the framework of participatory film-making have problematised to a much greater extent the interactions that undergird the filmic process (Kindon, 2003; Parr, 2007; Richardson-Ngwenya, 2012). From the perspective of such work, when sharing cameras and skills, relationships are at least as important as outputs. This paper, however, differs in terms of the types of interactions or encounters it is interested in - focusing more on their embodied and material dimension than on the sharing of competencies and expertises, which are often the focus of participatory video publications. It also argues that understandings of researcher-led video methods also have much to gain from examining and theorising the encounters that take place around a camera.

ii Original: 'nous déterminions l'objet de notre attention avant de l'enregistrer'.

iii Original: 'si je repère et je décris le cours d'une action dans le but spécifique de déterminer ce que je pourrais filmer, je considère l'événement non pas comme la circonstance particulière d'une expérience, mais comme une situation typique illustrant un modèle reproductible'.

iv Original: 'si je filme pour observer, c'est que j'observe "par" ce que je filme'.

${ }^{v}$ One of the reviewers rightly asked why I did not simply perform participant observation, if what I sought was an embodied understanding of practices. Among other things, health and safety issues, the multisited approach of the research, and the time-constraints of a $\mathrm{PhD}$ coupled with a teaching assistant job, all prevented me from enrolling as an apprentice in the park departments I researched - which would have been a good 'embodied' alternative.

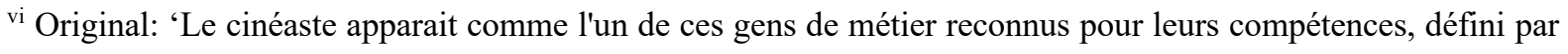
son rapport à l'objet technique'.

${ }^{\text {vii }}$ First days of ethnographic field work are intense affective experiences, which require a non-stop subtle negotiation of one's place within existing social relations. All my 'first days' seem to have stuck with me with great intensity. 